\title{
Alfa-amilase em frangos de corte: efeitos do balanço eletrolítico e do nível protéico da dieta ${ }^{1}$
}

\author{
Marcela Piedade Monteiro², George Henrique Kling de Moraes $^{2}$, Flavia Escapini Fanchiotti ${ }^{2}$, \\ Maria Goreti de Almeida Oliveira ${ }^{2}$, Ana Cláudia Peres Rodrigues ${ }^{3}$, Luiz Fernando Teixeira \\ Albino $^{4}$, Valéria Monteze Guimarães ${ }^{2}$, Flávio Medeiros Vieites ${ }^{2}$ \\ 1 Parte da dissertação da primeira autora apresentada à Universidade Federal de Viçosa para obtenção do título de "Magister Scientiae" \\ em Bioquímica Agrícola. Projeto financiado pelo CNPq. \\ 2 Departamento de Bioquímica e Biologia Molecular da UFV, 36571-000, Viçosa, MG. \\ ${ }^{3}$ Departamento de Bioquímica da UFJF, 36036-330, Juiz de Fora, MG. \\ ${ }^{4}$ Departamento de Zootecnia da UFV, 36571-000, Viçosa, MG.
}

RESUMO - Um experimento foi conduzido com pintos de corte macho para o estudo dos efeitos dos níveis de 20 e $23 \%$ de PB combinados com $0,50,100,150,200,250 \mathrm{mEq} / \mathrm{kg}$ de balanço dietético eletrolítico (BDE) sobre a atividade da $\alpha$-amilase pancreática de frangos de corte de 1 a 21 dias de idade. O delineamento utilizado foi o inteiramente casualizado. Dietas e água foram fornecidas ad libitum. Aos 1, 7, 14 e 21 dias, três aves de cada tratamento foram sacrificadas por deslocamento cervical para remoção do pâncreas, o qual foi removido, homogeneizado, congelado em nitrogênio líquido e liofilizado. Uma alíquota de cada amostra foi solubilizada em água deionizada e centrifugada a $7500 \mathrm{x} g$ por 3 minutos a $4^{\circ} \mathrm{C}$, para determinação da atividade da $\alpha$-amilase no sobrenadante. Aves alimentadas com $20 \%$ de PB apresentaram atividades específicas (U/mg de proteína) superiores à daquelas que receberam 23\%, exceto para os níveis de BDE de 100 a $200 \mathrm{mEq} / \mathrm{kg}$, aos 14 dias. Observou-se tendência de aumento da atividade específica dos 7 aos 14 dias e redução dos 14 aos 21 dias. Para maior atividade específica de $\alpha$-amilase, recomendam-se dietas com $20 \%$ de PB e $200 \mathrm{mEq} / \mathrm{kg}$ de BDE na fase pré-inicial e dietas com 20\% de PB e 135 a $250 \mathrm{mEq} / \mathrm{kg}$ de BDE para frangos de corte dos 8 aos 21 dias de idade.

Palavras-chave: $\alpha$-amilase, balanço eletrolítico, frangos, pâncreas, proteína dietética

\section{Alpha-amylase in broiler chickens: effects of electrolytic balance and dietary protein level}

\begin{abstract}
An experiment was conducted with male broiler chicks to study the effects of 20 and $23 \%$ of crude protein (CP) combined with $0,50,100,150,200,250 \mathrm{mEq} / \mathrm{kg}$ of dietary electrolytic balance (DEB) on the pancreatic $\alpha$-amylase activity from 1 to 21 days. A completely randomized factorial design was used. Feed and water were supplied ad libitum. At days 1, 7, 14 and 21, three birds from each treatment were sacrificed by cervical dislocation, pancreas were removed, homogeneized and frozen in liquid nitrogen which were then freeze-dried. An aliquot of each sample was solubilized with deionized water and centrifuged at $7500 \mathrm{x} g$ for three minutes at $4^{\circ} \mathrm{C}$. Activities of the pancreatic $\alpha$-amylase in the supernatants were determined Chicks fed $20 \%$ of CP showed specific activities (U/mg protein) higher than those fed $23 \%$, except for DEB levels from 100 to $200 \mathrm{mEq} / \mathrm{kg}$ at 14 days. A tendency to increase specific activity was observed from 7 to 14 days and to reduce from 14 to 21 days. The highest specific activity of pancreatic $\alpha$-amylase was observed in diets with $20 \% \mathrm{CP}$ and $200 \mathrm{mEq} / \mathrm{kg}$ of DEB from 1 to 7 days, diets with $20 \%$ of $\mathrm{CP}$ and 135 to $250 \mathrm{mEq} / \mathrm{kg}$ of DEB from 8 to 21 days of age.
\end{abstract}

Key Words: $\alpha$-amylase, broiler chicks, dietary protein, electrolytic balance, pancreas

\section{Introdução}

Na primeira semana de vida, o aparelho digestório de aves de corte cresce mais rápido que outros órgãos e tecidos. A alimentação exógena é fundamental logo nos primeiros dias de vida para maximizar o desenvolvimento do sistema digestório e possibilitar o crescimento desejado do animal em menor tempo (Sell et al., 1991; Noy \& Sklan, 1995;
Penz Jr. \& Vieira, 1998). As aves nascem com suprimento de nutrientes, incluindo enzimas digestivas, que se esgota rapidamente com a reduzida síntese e a elevada demanda na primeira semana (Nunes, 1998; Nitsan et al., 1991). As funções digestórias das aves passam por um processo de maturação com o avançar da idade, tanto da produção enzimática quanto do processo de absorção de nutrientes. A influência da idade da ave está relacionada à maturação 
dos órgãos que compõem o sistema digestório, incluindo a produção de enzimas digestivas, como a amilase (Rodrigues et al., 2001a; Lima et al., 2003).

No trato digestório, polissacarídeos são hidrolisados pela $\alpha$-amilase (EC 3.2.1.1) a dissacarídeos e oligossacarídeos. Esta endoglicosidase catalisa a hidrólise das ligações $\alpha-1,4-\mathrm{D}$-glicosídicas e possui pH ótimo em torno de 7,0 (Smith et al., 1988; Yoon \& Robyt, 2003). A hidrólise deficiente no lúmen intestinal promovida pelas enzimas pancreáticas provoca diminuição da digestibilidade aparente dos componentes da dieta e reduz o crescimento do animal (Corring \& Bourdon, 1987; Nitsan et al., 1991).

Atividade enzimática de $\alpha$-amilase é dependente de $\mathrm{Ca}^{++} \mathrm{e} \mathrm{Cl}^{-}$. Um Ca ${ }^{++}$é firmemente ligado a cada molécula da enzima e remove totalmente a supressão da atividade. A perda de $\mathrm{Ca}^{++}$causa várias mudanças conformacionais que aumentam a sensibilidade para que a digestão pela tripsina aconteça. O cloro também é necessário para a atividade de $\alpha$-amilase, entretanto, não está ligado à molécula como o $\mathrm{Ca}^{++}$. Outros íons ânions podem suprir o requerimento para atividade de $\alpha$-amilase em frangos, mas o $\mathrm{Cl}^{-}$é o mais eficiente (Moran Jr, 1982).

Alguns estudos têm comprovado que o balanço dietético eletrolítico (BDE) afeta o crescimento e a eficiência alimentar das aves (Simons et al., 1987; Karunajeewa \& Barr, 1988; Karunajeewa et al., 1986). Mongin \& Sauveur (1977) verificaram que o ótimo BDE da dieta $\left(\mathrm{Na}^{+}+\mathrm{K}^{+}-\mathrm{Cl}^{-}\right)$é de $250 \mathrm{mEq} / \mathrm{kg}$ para os frangos na fase de 1 a 21 dias e que a relação $\left(\mathrm{K}^{+}+\mathrm{Cl}^{-}\right) / \mathrm{Na}^{+}$deve ser maior que 1 (um). Os minerais $\mathrm{Na}, \mathrm{K}$ e $\mathrm{Cl}$ são importantes no desempenho do metabolismo, pela participação no balanço ácido-básico e na integridade dos mecanismos que regulam o transporte através das membranas celulares. O balanço desses minerais age no equilíbrio ácido-base das aves, podendo influenciar no seu desempenho e em outras funções fisiológicas (Judice et al., 2002).

A manutenção do equilíbrio ácido-base é essencial para os processos fisiológicos e bioquímicos (Sousa et al., 2002), pois pequenas alterações no $\mathrm{pH}$ sanguíneo podem afetar processos metabólicos relacionados ao crescimento, à resistência a doenças, à sobrevivência ao estresse pelo calor, entre outros (Murakami, 2000).

Segundo Aumaitre (1972), citado por Soares et al. (1999), a importância de se relacionar a atividade enzimática ao desenvolvimento do animal tem estimulado a realização de vários estudos com o objetivo de verificar a atividade de enzimas no trato digestório de animais nas diversas fases de desenvolvimento. As informações sobre o padrão de desenvolvimento de enzimas digestivas pancreáticas, suas secreções no duodeno e atividades nos conteúdos intestinais em frangos de corte durante os períodos iniciais de crescimento são importantes para a projeção e implementação de estratégias nutricionais e dietéticas para melhorar a utilização de nutrientes por aves jovens (Jin et al., 1998).

As respostas enzimáticas são fortemente influenciadas pelo $\mathrm{pH}$, que está relacionado ao equilíbrio eletrolítico do animal. O objetivo neste trabalho foi estudar os efeitos dos níveis de 20 e $23 \%$ de PB, combinados com $0,50,100,150$, 200 e $250 \mathrm{mEq} / \mathrm{kg}$ de BDE, sobre a atividade da $\alpha$-amilase pancreática em frangos de corte de 1 a 21 dias de idade.

\section{Material e Métodos}

O experimento foi realizado no setor de avicultura do Departamento de Zootecnia da Universidade Federal de Viçosa, MG, utilizando-se 720 pintos machos da linhagem comercial Ross, alojados em galpão experimental. Foram utilizados boxes de $1,25 \times 1,80 \mathrm{~m}$, com piso de cimento, cobertos com $10 \mathrm{~cm}$ de maravalha. Durante o período experimental, foi adotado programa de luz contínuo, com 24 horas de luz natural e artificial e, para aquecimento das aves do $1^{\underline{O}}$ ao $15^{\circ}$ dia, foram utilizadas lâmpadas infravermelho de $250 \mathrm{~W}$, de altura regulável. O fornecimento de ração e água foi à vontade durante todo o período experimental.

Foram utilizadas duas rações basais, formuladas à base de milho, farelo de soja e farelo de glúten de milho, contendo 20 e $23 \%$ de $\mathrm{PB}$, conforme recomendações nutricionais de Rostagno et al. (2000), de forma a conter balanço dietético eletrolítico (BDE) de $150 \mathrm{mEq} / \mathrm{kg}$ (Tabelas 1 e 2).

Os valores de BDE foram calculados utilizando-se a fórmula sugerida por Mongin (1981).

O delineamento experimental utilizado foi o inteiramente casualizado, em esquema fatorial 6 × 2 (seis níveis de BDE e dois níveis de $\mathrm{PB}$ ), com três repetições (em triplicata) de 20 aves por unidade experimental. Cada nível protéico foi suplementado com cloreto de amônio $\left(\mathrm{NH}_{4} \mathrm{Cl}\right)$ ou carbonato de potássio $\left(\mathrm{K}_{2} \mathrm{CO}_{3}\right)$ em substituição ao material inerte, de forma a se obterem níveis de 0,50,100,150,200 e $250 \mathrm{mEq} / \mathrm{kg}$ ) de BDE. As aves foram distribuídas uniformemente nos tratamentos com um dia de idade e peso médio de $45 \mathrm{~g}$.

Aos 1, 7, 14 e 21 dias, foram selecionadas ao acaso três aves de cada tratamento, as quais foram sacrificadas por deslocamento cervical para remoção do pâncreas. Após a remoção da gordura periférica, o pâncreas de cada ave foi congelado em nitrogênio líquido, homogeneizado, liofilizado e armazenado a $-20^{\circ} \mathrm{C}$. De cada amostra do material liofilizado, retirou-se $1 \mathrm{mg}$, o qual foi solubilizado em $1 \mathrm{~mL}$ de água 
Tabela 1 - Composição percentual das dietas experimentais Table 1 - Ingredient composition of the experimental diets

\begin{tabular}{|c|c|c|}
\hline $\begin{array}{l}\text { Ingrediente } \\
\text { Ingredient }\end{array}$ & $\begin{array}{c}\text { Ração, } 20 \% \\
\text { Diet, } 20 \%\end{array}$ & $\begin{array}{c}\text { Ração, } 23 \% \\
\text { Diet, } 23 \%\end{array}$ \\
\hline Milho & 60,870 & 55,913 \\
\hline \multicolumn{3}{|l|}{ Corn } \\
\hline Farelo de soja & 30,128 & 28,853 \\
\hline \multicolumn{3}{|l|}{ Soybean meal } \\
\hline Farelo de glúten de milho & - & 7,941 \\
\hline $\begin{array}{l}\text { Corn gluten meal } \\
\text { Óleo de soja }\end{array}$ & 2,571 & 1,632 \\
\hline \multicolumn{3}{|l|}{ Soybean oil } \\
\hline \multicolumn{2}{|l|}{ Limestone } & 1,027 \\
\hline Fosfato bicálcico & 1,860 & 1,826 \\
\hline \multicolumn{3}{|l|}{ Dicalcium phosphate } \\
\hline DL-metionina $(99 \%)$ & 0,285 & 0,130 \\
\hline \multicolumn{3}{|l|}{ DL-methionine } \\
\hline L-arginina $(99 \%)$ & 0,097 & - \\
\hline \multicolumn{3}{|l|}{ L-arginine } \\
\hline Glicina & 0,296 & - \\
\hline \multicolumn{3}{|l|}{ Glycine } \\
\hline L-lisina $\mathrm{HCl}(98 \%)$ & 0,332 & 0,295 \\
\hline \multicolumn{3}{|l|}{ L-lysine } \\
\hline L-treonina $(98,5 \%)$ & 0,139 & 0,007 \\
\hline \multicolumn{3}{|l|}{ L-threonine } \\
\hline L-triptofano $(99 \%)$ & 0,012 & - \\
\hline \multicolumn{3}{|l|}{ L-tryptophan } \\
\hline Sal comum & 0,469 & 0,460 \\
\hline \multicolumn{3}{|l|}{ Salt } \\
\hline \multicolumn{2}{|l|}{ Ammonium chloride } & 0,134 \\
\hline Cloreto de colina $(60 \%)$ & 0,100 & 0,100 \\
\hline \multicolumn{3}{|l|}{ Choline chloride } \\
\hline Premix vitamínico ${ }^{1}$ & 0,100 & 0,100 \\
\hline \multicolumn{3}{|l|}{ Vitamin premix } \\
\hline Premix mineral ${ }^{2}$ & 0,050 & 0,050 \\
\hline \multicolumn{3}{|l|}{ Mineral premix } \\
\hline Virginamicina $^{3}$ & 0,050 & 0,050 \\
\hline Anticoccidiano 4 & 0,055 & 0,055 \\
\hline \multicolumn{3}{|l|}{ Anticoccidial } \\
\hline Antioxidante ${ }^{5}$ & 0,010 & 0,010 \\
\hline $\begin{array}{l}\text { Antioxidant } \\
\text { Areia lavada (inerte) } \\
\text { Inert }\end{array}$ & 1,454 & 1,417 \\
\hline TOTAL & 100,00 & 100,00 \\
\hline
\end{tabular}

${ }^{1}$ Níveis de garantia por quilo do produto (Composition per kg of product): Vit. A, 10.000.000 UI; Vit. D3, 2.000.000 UI; Vit. E, 30.000 Ul; Vit. B1, 2,0 g; Vit. B6, 4,0 g; Ácido pantotênico (Pantothenic acid), 12,0g; Biotina (Biotin), $0,10 \mathrm{~g}$; Vit. K3, 3,0 g; Ácido fólico (Folic acid), 1,0 g; Ácido nicotínico (Nicotinic acid), 50,0 g; Vit. B12, 15.000 mcg; Se, 0, 25 g; e Veículo q.s.p. (Vehicle q.s.p.), $1.000 \mathrm{~g}$.

2 Níveis de garantia por quilo de produto (Composition per kg of product): $\mathrm{Mn}, 16,0$ g; Fe, 100,0 g; Zn, 100,0 g; Cu, 20,0 g; Co, 2,0 g; I, 2,0 g; e Veículo q.s.p. (Vehicle q.s.p.), $1.000 \mathrm{~g}$.

3 Virginamicina (Stafac - 50\%).

4 Salinomicina (Coxistac - 12\%)

${ }^{5}$ Hidroxi Butil Tolueno (BHT).

deionizada gelada utilizando-se agitador. As amostras foram centrifugadas a $7500 \times \mathrm{g}$ por 3 minutos a $4^{\circ} \mathrm{C} . \mathrm{O}$ sobrenadante foi utilizado para determinação da atividade da enzima $\alpha$-amilase.

A atividade de $\alpha$-amilase foi determinada por espectrofotometria, empregando-se kit produzido pela In Vitro Diagnóstica, com base no princípio de que a $\alpha$-amilase
Tabela 2 - Composição calculada das dietas Table 2 - Calculated composition of the diets

\begin{tabular}{|c|c|c|}
\hline Item & $\begin{array}{c}\text { Ração, } 20 \% \\
\text { Diet, } 20 \%\end{array}$ & $\begin{array}{c}\text { Ração, } 23 \% \\
\text { Diet, } 23 \%\end{array}$ \\
\hline $\begin{array}{l}\text { Energia metabolizável (kcal/ kg) } \\
\text { Metabolizable energy }\end{array}$ & 3.000 & 3.000 \\
\hline $\begin{array}{l}\text { Proteína bruta }(\%) \\
\text { Crude protein }\end{array}$ & 20,00 & 23,00 \\
\hline Cálcio (\%) & 0,960 & 0,960 \\
\hline $\begin{array}{l}\text { Calcium } \\
\text { Fósforo total }(\%)\end{array}$ & 0,668 & 0,679 \\
\hline $\begin{array}{l}\text { Total phosphorus } \\
\text { Fósforo disponível (\%) } \\
\text { Available phosphorus }\end{array}$ & 0,450 & 0,450 \\
\hline $\begin{array}{l}\text { Sódio }(\%) \\
\text { Sodium }\end{array}$ & 0,225 & 0,222 \\
\hline $\begin{array}{l}\text { Potássio (\%) } \\
\text { Potassium }\end{array}$ & 0,737 & 0,712 \\
\hline $\begin{array}{l}\text { Cloro }(\%) \\
\text { Chlorine }\end{array}$ & 0,484 & 0,457 \\
\hline $\begin{array}{l}\text { Arginina total }(\%) \\
\text { Arginine }\end{array}$ & 1,324 & 1,321 \\
\hline $\begin{array}{l}\text { Arginina digestível (\%) } \\
\text { Digestible arginine }\end{array}$ & 1,260 & 1,260 \\
\hline $\begin{array}{l}\text { Glicina + serina }(\%) \\
\text { Glycine + serine }\end{array}$ & 2,096 & 2,096 \\
\hline $\begin{array}{l}\text { Metionina }+ \text { cistina total }(\%) \\
\text { Methionine }+ \text { Cystine }\end{array}$ & 0,890 & 0,901 \\
\hline $\begin{array}{l}\text { Metionina }+ \text { cistina digestível }(\%) \\
\text { Digestible methionine }+ \text { cystine }\end{array}$ & 0,815 & 0,815 \\
\hline $\begin{array}{l}\text { Lisina total }(\%) \\
\text { Lysine }\end{array}$ & 1,250 & 1,252 \\
\hline $\begin{array}{l}\text { Lisina digestível (\%) } \\
\text { Digestible lysine }\end{array}$ & 1,143 & 1,143 \\
\hline $\begin{array}{l}\text { Treonina total }(\%) \\
\text { Threonine }\end{array}$ & 0,874 & 0,873 \\
\hline $\begin{array}{l}\text { Treonina digestível (\%) } \\
\text { Digestible threonine }\end{array}$ & 0,766 & 0,766 \\
\hline $\begin{array}{l}\text { Triptofano total }(\%) \\
\text { Tryptophan }\end{array}$ & 0,245 & 0,243 \\
\hline $\begin{array}{l}\text { Triptofano digestível (\%) } \\
\text { Digestible tryptophan }\end{array}$ & 0,221 & 0.221 \\
\hline $\begin{array}{l}\text { Balanço eletrolítico }(\mathrm{mEq} / \mathrm{kg}) \\
\text { Electrolitic balance }\end{array}$ & 150 & 150 \\
\hline
\end{tabular}

promove a hidrólise do amido com a liberação de moléculas de maltose e dextrina, resultando na cor azul decorrente da complexação do iodo com o amido não hidrolisado. A atividade de $\alpha$-amilase é inversamente proporcional à intensidade de cor azul, sendo calculada pela comparação com um controle de substrato. A leitura da cor desenvolvida é realizada a $660 \mathrm{~nm}$ e os valores são expressos em unidades da amilase por $100 \mathrm{~mL}$ da amostra (U\%).

A determinação da concentração de proteína no homogenato do pâncreas foi realizada pelo método descrito por Warburg \& Christian (1941), citados por Whitaker \& Granum (1980), que utiliza as leituras de absorção a 260 e $280 \mathrm{~nm}$. O valor da leitura a $280 \mathrm{~nm}$ é dividido pelo valor a $260 \mathrm{~nm}$, obtendo-se um fator para correção da presença de resíduos de tirosina, triptofano e ácidos nucléicos. Multi- 
Tabela 3 - Tratamentos constituídos pelas rações basais (20 e $23 \%$ de PB) suplementadas com $\mathrm{NH}_{4} \mathrm{Cl}_{\text {ou }} \mathrm{K}_{2} \mathrm{CO}_{3}$ Table 3 - Basal diets with 20 and $23 \% \mathrm{CP}$ and supplemented with $\mathrm{NH}_{4} \mathrm{Cl}$ or $\mathrm{K}_{2} \mathrm{CO}_{3}$

\begin{tabular}{|c|c|c|c|c|c|}
\hline $\begin{array}{l}\mathrm{BDE}(\mathrm{mEq} / \mathrm{kg}) \\
D E B\end{array}$ & $\begin{array}{c}\text { Ração basal }(\mathrm{kg}) \\
\text { Basal diet }\end{array}$ & $\begin{array}{l}\text { Inerte }(\mathrm{kg}) \\
\text { Inert }\end{array}$ & $\mathrm{NH}_{4} \mathrm{Cl}(\mathrm{kg})$ & $\mathrm{K}_{2} \mathrm{CO}_{3}(\mathrm{~kg})$ & Total $(\mathrm{kg})$ \\
\hline 0 & 98,5 & 0,693 & 0,807 & - & 100 \\
\hline 50 & 98,5 & 0,962 & 0,538 & - & 100 \\
\hline 100 & 98,5 & 1,231 & 0,269 & - & 100 \\
\hline 150 & 98,5 & 1,500 & - & - & 100 \\
\hline 200 & 98,5 & 1,151 & - & 0,349 & 100 \\
\hline 250 & 98,5 & 0,802 & - & 0,698 & 100 \\
\hline
\end{tabular}

$\mathrm{NH}_{4} \mathrm{Cl}$ - peso molecular (U.M.A.) (molecular weight) $=53,45$; pureza (purity) $99,5 \%$.

$\mathrm{K}_{2} \mathrm{CO}_{3}$ - peso molecular (U.M.A.) (molecular weight) = 138,20; pureza (purity) $99,0 \%$.

plicando-se a leitura a $280 \mathrm{~nm}$ pelo fator de correção e pelo fator de diluição da amostra, obtém-se a concentração de proteína em $\mathrm{mg} / \mathrm{mL}$ de amostra. A diluição utilizada neste estudo foi 1:10.

As análises estatísticas dos dados foram realizadas por meio do programa Sistema para Análises Estatísticas e Genéticas - SAEG (UFV, 2000), efetuando-se análise de variância com posterior regressão polinomial.

\section{Resultados e Discussão}

Em frangos de corte aos 7 dias de idade, não foram observadas interação níveis de $\mathrm{PB} \times \mathrm{BDE}(\mathrm{P}>0,05)$, mas houve efeito $(\mathrm{P}<0,01)$ do nível de proteína sobre atividade enzimática para as rações com $20 \%$ de proteína, as quais proporcionaram maior atividade específica da enzima.

Quanto à atividade enzimática, a variação tende a ser grande entre os animais dentro do mesmo tratamento nutricional (Carmo et al., 2003; Rodrigues et al., 2001a,b; Carelli et al., 2000; Guimarães et al., 1997). Os resultados são apresentados na Tabela 5 .

Aos 14 dias de idade, a interação PB $\times$ BDE não foi significativa $(\mathrm{P}>0,05)$. Verificou-se, no entanto, efeito quadrático dos níveis de $\mathrm{BDE}(\mathrm{P}<0,01)$ sobre a atividade específica, indicando que o nível de $134,87 \mathrm{mEq} / \mathrm{kg}$ de BDE pode causar maior atividade específica de $\alpha$-amilase (Tabela 4).

A interação níveis de $\mathrm{PB} \times \mathrm{BDE}$ foi significativa $(\mathrm{P}<0,05)$ em frangos aos 21 dias de idade. Entretanto, não existe regressão linear ou quadrática capaz de explicar a variação de BDE sobre atividade enzimática específica para 20 e $23 \%$ de PB.

Em estudo com frangos de corte de 1 a 7 dias, com 20 e 23\% de PB e diferentes níveis de BDE, Vieites (2003) verificou maior ganho de peso com BDE de 129 e $136 \mathrm{mEq} / \mathrm{kg}$ (para 20 e $23 \%$ de PB, respectivamente) e melhor consumo de ração com BDE de $167 \mathrm{mEq} / \mathrm{kg}$, independentemente do nível protéico.
Tabela 4 - Equação de balanço dietético eletrolítico (BDE) para atividade específica de $\alpha$-amilase pancreática de frangos de corte aos 14 dias

Table 4 - Equations of dietary eletrolitic balance (DEB) for specific activities of pancreatic a-amylase of broiler chicks with 14 days old

\begin{tabular}{cccc}
\hline $\begin{array}{c}\text { Equação } \\
\text { Equation }\end{array}$ & $\mathrm{R}^{2}$ & Máx & $\begin{array}{c}\mathrm{BDE} \\
\text { DEB }\end{array}$ \\
& & $(\mathrm{mEq} / \mathrm{kg})$ & \\
\hline$\hat{\mathrm{Y}}=25371+776,6 \mathrm{X}-2,879 \mathrm{X}^{2}$ & 0,66 & 77742,27 & 134,87 \\
\hline
\end{tabular}

Segundo Araújo et al. (2001), uma dieta deve conter exatamente os níveis de aminoácidos exigidos para mantença e máxima deposição protéica. Relacionando essas sugestões ao fato de as aves aos 7 dias de idade terem o aparelho digestório imaturo, é possível que o nível de $23 \%$ de PB tenha causado excesso de aminoácidos catabolisados. Assim, o nível de $20 \%$ de PB, neste estudo, foi melhor para o desenvolvimento do aparelho digestório.

Em frangos aos 14 dias de idade, no entanto, os níveis de $\mathrm{PB}$ não influenciaram significativamente a atividade enzimática, corroborando relatos de Borges et al. (2002), que verificaram, em frangos no período inicial, que os níveis de $\mathrm{PB}$ não afetaram o desempenho e concluíram que $21 \%$ de $\mathrm{PB}$ nas dietas pré-inicial e inicial atendem às necessidades dos frangos alimentados com dieta contendo $2.900 \mathrm{kcalEM} / \mathrm{kg}$

As aves com 21 dias de idade alimentadas com a dieta contendo $20 \%$ de PB apresentaram atividade específica maior para todos os níveis de BDE, provavelmente em razão do excesso de aminoácidos na ração com $23 \%$ de PB e da formação de ácido úrico (Ribeiro et al., 1995).

Maiorka et al. (1998) sugeriram como ótimo o valor de $\mathrm{BDE}$ de $140 \mathrm{mEq} / \mathrm{kg}$ para dietas pré-iniciais no desempenho de frangos de corte, próximo ao observado neste trabalho.

Animais aos 14 dias de idade apresentaram valor de atividade específica de $\alpha$-amilase menor que os obtidos por Vieites (2003) para melhor ganho de peso e conversão 
alimentar (BDE entre 166 e $197 \mathrm{mEq} / \mathrm{kg}$ ) para frangos de corte de 1 a 14 dias de idade.

Murakami et al. (2001) encontraram, para máximo crescimento de frangos de corte de 21 a 42 dias de idade, níveis de 249 a $261 \mathrm{mEq} / \mathrm{Kg}$ de BDE. Resultados similares, porém em intervalo maior, foram relatados por Oviedo-Rondón et al. (1999) para frangos de 1 a 21 dias de idade. Estes autores sugeriram para melhor conversão alimentar BDE de 246 a $315 \mathrm{mEq} / \mathrm{kg}$. Neste estudo, observou-se que os níveis de $250 \mathrm{mEq} / \mathrm{kg}$ de BDE e $20 \%$ de PB permitiram maiores valores de atividade específica de $\alpha$-amilase.

A atividade específica de $\alpha$-amilase pancreática nos pintos de 1 dia de idade foi, em média, $45.431 \mathrm{U} / \mathrm{mg}$ de proteína, superior aos níveis das atividades enzimáticas dos frangos aos 7 dias de idade, exceto naqueles alimentados com dieta contendo $20 \%$ de PB e 50 e $200 \mathrm{mEq} / \mathrm{kg}$ de BDE. Observou-se tendência à queda da atividade específica de $\alpha$-amilase pancreática do $1^{\circ} \underline{\mathrm{O}}$ ao $7 \underline{0}$ dia de idade, aumento da atividade dos 7 aos 14 dias e redução dos 14 aos 21 dias de idade.

Esses resultados corroboram os obtidos por alguns autores (Jin et al., 1998; Carmo et al., 2003), que afirmam que as atividades das enzimas digestivas em frangos de corte podem sofrer alterações com a dieta e a idade.

Quando o ovo eclode, a ave não está totalmente preparada para os desafios ambientais. Durante o desenvolvimento embrionário, nutrientes são retirados do ovo e, no momento da eclosão, algum suprimento de nutriente residual disponível na gema do ovo é absorvido na cavidade peritoneal. Este suprimento é esgotado em frangos de corte de 4 a 5 dias (Sell, 1996). Reservas de enzimas pancreáticas esgotam rapidamente porque a síntese neste período é menor que o requerimento para secreção no intestino e para manter a concentração inicial (Nitsan et al., 1991).

Alguns autores (Nitsan et al., 1991; Nir et al., 1993; Carmo et al., 2003) afirmam que a síntese de enzimas digestivas no pâncreas de frangos é limitada durante o início do crescimento e aumenta até o valor máximo por volta do $10^{\underline{0}}$ dia pós-eclosão, quando a taxa de crescimento relativo é máxima, indicando a possibilidade de relação entre esses dois fatores. Dunnington \& Siegel (1995) verificaram que a atividade relativa de amilase pancreática reduziu entre os dias 6 e 8, continuou diminuindo até o dia 10 e aumentou posteriormente. Crescimento relativamente alto da atividade específica da amilase foi registrado entre 0 e 1 dia de idade por Sell et al. (1991). Nir et al. (1993) encontraram atividade específica de $\alpha$-amilase maior no dia da eclosão, com diminuição aos 8 dias de idade.

A secreção pancreática de frangos contém enzimas proteolíticas, amilolíticas e lipolíticas, mas a atividade
Tabela 5 - Médias da atividade específica de $\alpha$-amilase pancreática (U/mg de proteína) de frangos de corte consumindo rações com 20 e $23 \%$ de PB submetidos a diferentes balanços eletrolíticos

Table 5 - $\quad$ Average activities of pancreatic $\alpha$-amylase (U/mg protein) of broiler chicks at days 1, 7, 14 and 21 fed diet with 20 and 23\% of $\mathrm{CP}$ and different levels of eletrolitic balance

\begin{tabular}{|c|c|c|c|}
\hline \multicolumn{4}{|c|}{$\begin{array}{l}\text { Idade (dias) } \\
\text { Age (days) }\end{array}$} \\
\hline \multirow[t]{3}{*}{1} & & \multicolumn{2}{|c|}{45431} \\
\hline & \multirow{2}{*}{$\begin{array}{r}\text { Balanço eletrolítico } \\
\text { Eletrolitic balance } \\
(\mathrm{mEq} / \mathrm{kg})\end{array}$} & \multicolumn{2}{|c|}{$\begin{array}{l}\text { Níveis de PB } \\
\text { Crude protein level }\end{array}$} \\
\hline & & $20 \%$ & $23 \%$ \\
\hline \multirow{6}{*}{7} & 0 & 32094 & 20749 \\
\hline & 50 & 47072 & 20366 \\
\hline & 100 & 33146 & 40235 \\
\hline & 150 & 38355 & 16104 \\
\hline & 200 & 56027 & 15832 \\
\hline & 250 & 26972 & 13149 \\
\hline \multirow{6}{*}{14} & 0 & 47860 & 25486 \\
\hline & 50 & 47240 & 34034 \\
\hline & 100 & 43974 & 80095 \\
\hline & 150 & 92995 & 104775 \\
\hline & 200 & 56518 & 78532 \\
\hline & 250 & 33652 & 32537 \\
\hline \multirow{6}{*}{21} & 0 & 42589 & 36193 \\
\hline & 50 & 47216 & 9857 \\
\hline & 100 & 46857 & 40188 \\
\hline & 150 & 45884 & 42902 \\
\hline & 200 & 36067 & 33763 \\
\hline & 250 & 54079 & 33736 \\
\hline
\end{tabular}

dessas enzimas são pobremente desenvolvidas até os 7 dias após o nascimento. A atividade de amilase aumenta rapidamente durante os primeiros 14 dias de idade e parece estabilizar depois dos 21 dias (Jin et al., 1998). Rodrigues et al. (2001b) verificaram peso relativo máximo de pâncreas, fígado e intestino de frangos e atividade específica de amilase mais alta aos 14 dias de idade. Resultados semelhantes foram reportados por Lima et al. (2003), que encontraram atividade das enzimas pancreáticas maior, em quilo de peso vivo, no $14^{\circ}$ dia, diminuindo com o avançar da idade das aves (até 42 dias de idade).

\section{Conclusões}

Na fase pré-inicial, de 1 a 7 dias, recomendam-se dietas com $200 \mathrm{mEq} / \mathrm{kg}$ de BE e $20 \%$ de PB para maior atividade específica de $\alpha$-amilase pancreática.

Para frangos de corte dos 8 aos 21 dias de idade, propõe-se o uso de dietas com BE de 135 a $250 \mathrm{mEq} / \mathrm{kg}$ de BE e $20 \%$ de PB para maior atividade específica de $\alpha$-amilase pancreática e desenvolvimento adequado do aparelho digestório. 


\section{Literatura Citada}

ARAÚJO, L.F.; JUNQUEIRA; O.M.; ARAÚJO, C.S.S. et al. Proteína bruta e proteína ideal para frangos de corte no período de 1 a 21 dias de idade. Revista Brasileira de Ciência Avícola, v.3, n.2, p.157-162, 2001 .

BORGES, S.A.; MAIORKA, A.; LAURENTIZ, A.C. et al. Balanço eletrolítico para frangos de corte na primeira semana de idade. Revista Brasileira de Ciência Avícola, v.4, n.2, p.149-153, 2002 .

CARELLI, M.C.S.; MORAES, G.H.K.; OLIVEIRA, M.G.A. et al. Dietary effects of L- glutamic acid combined with vitamin D in the activities of chymo and pancreas amylase of chicks. In: REUNIÃO ANUAL DA SOCIEDADE BRASILEIRA DE BIOQUÍMICA, 30., 2000, Caxambu. Resumos... Caxambu: Sociedade Brasileira de Bioquímica, 2000. p.26.

CARMO, H.M.; MORAES, G.H.K.; FREITAS, H.T. et al. Development of pancreas lipase and $\beta$-amylase of chickens from birth to 21 days of age. In: REUNIÃO ANUAL DA SOCIEDADE BRASILEIRA DE BIOQUÍMICA, 30., Caxambu, 2003. Anais... São Paulo: Sociedade Brasileira de Bioquímica, 2003. p. 140 .

CORRING, T.; BOURDON, D. Exclusion of pancreatic exocrine secretion from intestine in the pig: existence of a digestive tract and the pig: existence of a digestive compensation. Journal Nutrition, v.107, n.7, p.1216-1221, 1987.

DUNNINGTON, E.A.; SIEGEL, P.B. Enzyme activity and organ development in newly hatched chicks selected for high or low eight-week body weight. Poultry Science, v.74, n.5, p.761770,1995

GUIMARÃES, V.M.; RIBEIRO, M.; MORAES, G.H.K. Effects of dietarynonessential amino acids and pyridoxine in the chick liver glutamic-oxaloacetate transaminase activities. In: REUNIÃO ANUAL DA SOCIEDADE BRASILEIRA DE BIOQUíMICA, 26., 1997, Caxambu. Resumos... Caxambu: Sociedade Brasileira de Bioquímica, 1997. p.26.

JIN, S.H.; CORLESS, A.; SELL, J.L. Digestive system development in post-hatch poultry. World's Poultry Science Journal, v.54, n.4, p.335-345, 1998.

JUDICE, M.P.M.; BERTECHINI, A.G.; MUNIZ, J.A. et al. Balanço cátion-aniônico das rações e manejo alimentar para poedeiras de segundo ciclo. Ciência Agrotecnica, v.26, n.3, p.598-609, 2002.

KARUNAJEEWA, H.; BARR, D. A. Influence of dietary electrolyte balance, source of added potassium and anticoccidial agents on the performance of male broilers. British Poultry Science, v.29, n.1, p.137-147, 1988.

KARUNAJEEWA, H.; BARR, D.A.; FOX, M. Effect of dietary phosphorus concentration and electrolyte balance on the growth performance of broiler chickens. British Poultry Science, v.27, n.4, p.601-612, 1986.

LIMA, A.C.F.; PIZAURO JR., J.M.; MACARI, M. et al. Efeito do uso de probiótico sobre o desempenho e atividade de enzimas digestivas de frangos de corte. Revista Brasileira de Zootecnia, v.32, n.1, p.200-207, 2003.

MAIORKA, A.; MAGRO, N.; BARTLS, H.A. et al. Efeito do nível de sódio e diferentes relações entre sódio, potássio e cloro em dietas pré-iniciais no desempenho de frangos de corte. In: REUNIÃO ANUAL DA SOCIEDADE BRASILEIRA DE ZootecniA, 35., 1998, Botucatu. Anais... Botucatu: Sociedade Brasileira de Zootecnia, 1998. p.478-480.

MONGIN, P. Recent advances in dietary anion-cation balance: application in poultry. Procedure Nutrition Society, v.40, n.3, p.285-294, 1981.

MONGIN, P.; SAUVEUR, B. Interrelationships between mineral nutrition, acid-base, growth and cartilage abnormalities. Proceedings Poultry Science, v.56, n.12, p.235-247, 1977 .
MORAN JR., E.T. Starch digestion in fowl. Poultry Science, v.61, n.7, p.1257-1267, 1982.

MURAKAMI, A.E. Balanço eletrolítico da dieta e sua influência sobre o desenvolvimento dos ossos de frangos. In: CONFERÊNCIA APINCO DE CIÊNCIA E TECNOLOGIA AVÍCOLA, 2000, Campinas. Anais... Campinas: Fundação APINCO de Ciência e Tecnologia Avícolas, 2000. p.33-61

MURAKAMI, A.E.; OVIEDO-RONDÓN, E.O.; MARTINS, E. N. et al. Sodium and chloride requirements of growing broiler chickens (twenty-one to forty-two days of age) fed cornsoybean diets. Poultry Science, v.80, n.3, p.289-294, 2001.

NIR, I.; NITSAN, Z.; MAHAGNA, M. Comparative growth and development of the digestive organs and of some enzymes in broiler and egg type chicks after hatching. British Poultry Science, v.34, n.3, p.523-532, 1993.

NITSAN, Z.; BEN-AVRAHAM, G.; ZOREF, Z. et al. Growth and development of the digestive organs and some enzymes in broiler chicks after hatching. British Poultry Science, v.32, n.3, p.515-523, 1991.

NOY, Y.; SKLAN, D. Digestion and absorption in the young chick Poultry Science, v.74, n.2, p.366-373, 1995

NOY, Y.; SKLAN, D. Post hatch development in poultry. Journal Apply Poultry Research, v.6, p.344-354, 1997.

NUNES, I.J. Nutrição animal básica. 2.ed. Belo Horizonte: FEPMVZ Editora, 1998. 387p.

OVIEDO-RONDÓN, E.O.; MURAKAMI, A.E.; MARTINS, E.N. et al. Sodium and chloride nutritional requirements for young broiler chickens ( 1 to 21 days of age). In: POULTRY SCIENCE ASSOCIATION ANNUAL MEETING, 88., Arkansas, 1999. Proccedings... Fayetteville: Poultry Science Association, 1999. p.63.

PENZ JR., A.M.; VIEIRA, S.L. Nutrição na primeira semana. In: SIMPÓSIO INTERNACIONAL SOBRE MANEJO DE PINTOS DE CORTE, 1998, Campinas. Anais... Campinas: Fundação APINCO de Ciência e Tecnologia Avícolas, 1998. p.121-139.

RIBEIRO, M.; MORAES, G.H.K.; SANT'ANNA, R. et al. Efeitos de ácido L-glutâmico, L-alanina e L-prolina da dieta em pintos de corte: II - glutamato desidrogenase (GDH) hepática, aminoácidos e ácido úrico séricos. Revista Brasileira de Zootecnia, v.24, n.5, p.778-787, 1995

RODRIGUES, A.C.P.; MORAES, G.H.K.; OLIVEIRA, M.G.A. et al. Activities of chymo lipase, $\alpha$-amylase and trypsin and small intestinal morphology of chickens from birth to 21 days of age. In: REUNIÃO ANUAL DA SOCIEDADE BRASILEIRA DE BIOQUÍMICA, 30., Caxambu, 2001. Resumos... Caxambu: Sociedade Brasileira de Bioquímica, 2001. p.119a.

RODRIGUES, A.C.P.; MORAES, G.H.K.; OLIVEIRA, M.G.A. et al. Activities of pancreas lipase, $\alpha$-amylase and trypsin and organ development of chickens from birth to 21 days of age. In: REUNIÃO ANUAL DA SOCIEDADE BRASILEIRA DE BIOQUÍMICA, 30., Caxambu, 2001. Resumos... Caxambu: Sociedade Brasileira de Bioquímica, 2001. p.121b.

ROSTAGNO, H.S. Tabelas brasileiras para aves e suínos: composição de alimentos e exigências nutricionais. Viçosa, MG: Universidade Federal de Viçosa, 2000. 141p.

SELL, J.L.; ANGEL, C.R.; PIQUER, F.J. et al. A. Development patterns of selected characteristics of the gastrointestinal tract of young turkeys. Poultry Science, v.70, n.5, p.1200-1205, 1991 .

SELL, J.L. Physiological limitations and potential for improvement in gastrointestinal tract function of poultry. Journal of Applied Poultry Research, v.5, p.96-101, 1996.

SIMONS, P.C.M.; HULAN, H.W.; TEUNIS, G.P. et al. Effect of dietary cation-anion balance on acid-base status and incidence of tibial discondroplasia of broiler chickens. Nutrition Reports International, v.35, n.3, p.591-600, 1987.

SMITH, E.L.; HILL, R.L.; LEHMAN, I.R. et al. Bioquímica: mamíferos. 7.ed. Rio de Janeiro: Guanabara Koogan, 1988. $620 \mathrm{p}$. 
SOARES, J.M.; OLIVEIRA, M.G.A.; DONZELE, J.L. et al. Atividade enzimática da tripsina e quimiotripsina do pâncreas e do quimo de leitões do nascimento aos 35 dias de idade. Revista Ceres, v.46, n.264, p.125-139, 1999.

SOUZA, B.B.; BERTECHINI, A.G.; TEIXEIRA, A.S. et al. Efeito da suplementação de cloreto de potássio na dieta sobre o equilíbrio ácido-básico e o desempenho de frangos de corte no verão. Ciência Agrotécnica, v.26, n.6, p.1297-1304, 2002.

UNIVERSIDADE FEDERAL DE VIÇOSA - UFV. SAEG - Sistema de análises estatísticas e genéticas. Viçosa: MG: 2000 (Versão 8.0).

VIEITES, F.M.; MORAES, G.H.K.; ALBINO, L.F.T. et al. Balanço eletrolítico e níveis de proteína bruta sobre parâmetros sanguíneos e ósseos de frangos de corte aos 21 dias de idade. In: REUNIÃO ANUAL DA SOCIEDADE BRASILEIRA DE ZOOTECNIA, 40., 2003, Santa Maria. Anais... Santa Maria: Sociedade Brasileira de Zootecnia, 2003.
WHITAKER, J.R.; GRANUM, P.E. An absolute method for protein determination based on difference in absorbance at 235 and 280 nm. Analytical Biochemistry, v.109, p.156-159, 1980

YOON, S.H.; ROBYT, J.F. Study of the inhibition of four alpha amylases by acarbose and its $4^{\mathrm{IV}}-\alpha$-maltohexaosyl and $4^{\mathrm{IV}}-\alpha$ maltododecaosyl analogues. Carbohydrate Research, v. 338 , n.19, p.1969-1980, 2003.

Recebido: 21/02/05 